\title{
EXPERIMENTAL RESEARCH AIMED AT DETERMINING THE FORCE AND ENERGY OF THE IMPACT OF MOTORCYCLIST'S HEAD AGAINST A MOTOR CAR SIDE DURING A ROAD ACCIDENT
}

\author{
TOMASZ PUSTY ${ }^{1}$, LEON PROCHOWSKI $^{1,2} \&$ MIROSŁAW GIDLEWSKI ${ }^{1,3}$ \\ ${ }^{1}$ Automotive Industry Institute, Warszawa, Poland. \\ ${ }^{2}$ Military University of Technology, Warszawa, Poland. \\ ${ }^{3}$ University of Technology and Humanities, Radom, Poland.
}

\begin{abstract}
The paper covers both experimental tests and analytical calculations. The calculations were based on a frame-by-frame analysis of a video record of the experiment and on results of measurements of the motorcyclist, motorcycle, and car acceleration vector components. They enabled determining the forces that acted in the areas of contact between the motorcycle and motorcyclist with the vehicle during the collision.

A few experiments were carried out, which included the physical reconstruction of a road accident where a motorcyclist frontally hit a motor car side and the related laboratory examinations of motorcycle helmets and helmet liner materials. Based on the experimental test results, the position and velocity of motorcyclist's head in relation to his/her torso and to the car side in the initial phase of the accident were determined. The forces developing in the area of motorcyclist's head impact against the car side caused deformation of car body, helmet shell, and inner helmet material. The analysis covered an impact capable to result in a situation where the car body reaction force applied to the helmet might cause the energy-absorbing liner and comfort padding of the helmet to be deformed to such an extent that the said force would directly act on motorcyclist's head.

The tests carried out revealed what part of the kinetic energy of motorcyclist's body, dissipated during an accident, depended on the course of deformation of vehicle body (in the place struck by motorcyclist's head) and helmet and on the type of helmet liner material. An important outcome of the experimental research and computations is the evaluation of the effectiveness of helmet materials and their suitability for the protection of motorcyclist's head during a road accident.

Keywords: motorcycle accidents, motorcyclist safety, research helmets
\end{abstract}

\section{INTRODUCTION}

The annual statistics of road accidents in Poland and Europe show that a great number of people die in traffic accidents. Injuries that motorcyclists incur in accidents are the result of forces acting on a human body impacting an obstacle.

The issue of a motorcycle hitting the side of the car was shown in an interesting way in papers [1-3]. These studies provide a good basis for analysing the course of an impact of a motorcycle striking the side of a car. However, the issue of determining the force and energy of a human head hitting the body of a vehicle was not addressed in any of the analysed papers.

The main purpose of the study is to determine the force of the motorcyclist's head hitting the obstacle and to identify on its basis the components of the energy balance of the collision process, which are related to the course of deformation of the body of the car at the place of the impact and the course of the helmet deformation. The additional purpose of the study is to assess the effectiveness and suitability of materials for filling the inner layer of the motorcycle helmet, since these materials require further improvement $[4,5]$. 
The basis for the conducted calculations were results of several research experiments carried out at the Automotive Insdustry Institute in Warsaw, where:

- a road accident involving a motorcycle hitting frontally the side of the car was recreated;

- helmets and materials that could be used as internal helmet lining were tested.

In the analysed case, the motorcycle with a motorcyclist sitting on it, hit with the speed of $v_{p}=49.5 \mathrm{~km} / \mathrm{h}$ the side of a stationary vehicle (Fig. 1). Main components of the energy dissipated during the motorcycle deformation process as a result of interaction with the car and the car deformation were calculated and shown in studies [6, 7]. Papers [8,9] consider the work of the force deforming the car without clear separation of the work resulting from the impact of the motorcycle and motorcyclist. Currently, the attention has been focused on calculating the components of the energy balance related to the deformation of the car and the helmet as a result of the impact of the head of the motorcyclist.

Before hitting the side of the car, the motorcyclist and the motorcycle were moving progressively at the initial speed of $\mathrm{v}_{\mathrm{P}}$. The kinetic energy of the motorcyclist (EK1) immediately prior to the collision was:

$$
E K 1=\frac{m_{1} v_{P}^{2}}{2}
$$

where:

$\mathrm{m}_{1}$ - the mass of the motorcyclist.

During the experiment, at $\mathrm{t}=0-0.074 \mathrm{~s}$ the front of the motorcycle deforms and its speed is reduced. The motorcyclist moves along the seat and onto the fuel tank. At the same time, the tilting angle of his torso increases by about 20 degrees and the head by 26 degrees in the direction of the movement (Fig. 1). As a result of both these processes (the motorcycle deformation and tilting), the head speed increased from 49.5 to $51.1 \mathrm{~km} / \mathrm{h}$, and its height was reduced by $0.1 \mathrm{~m}$. This resulted in the motorcyclist's head hitting the lateral edge of the car bodywork roof (Figs. $1 \& 3$ ). Throughout the whole experiment, the motorcyclist's head was protected by the helmet.

\section{THE DETERMINATION OF FORCES IN THE AREA OF THE HEAD HITTING THE SIDE OF THE CAR}

The measured courses of components of the acceleration vector of the head $\left(\mathrm{a}_{\mathrm{Gx}}, \mathrm{a}_{\mathrm{Gz}}\right)$ and torso $\left(\mathrm{a}_{\mathrm{Tx}}, \mathrm{a}_{\mathrm{Tz}}\right)$ of the motorcyclist were used to determine components of the acceleration in

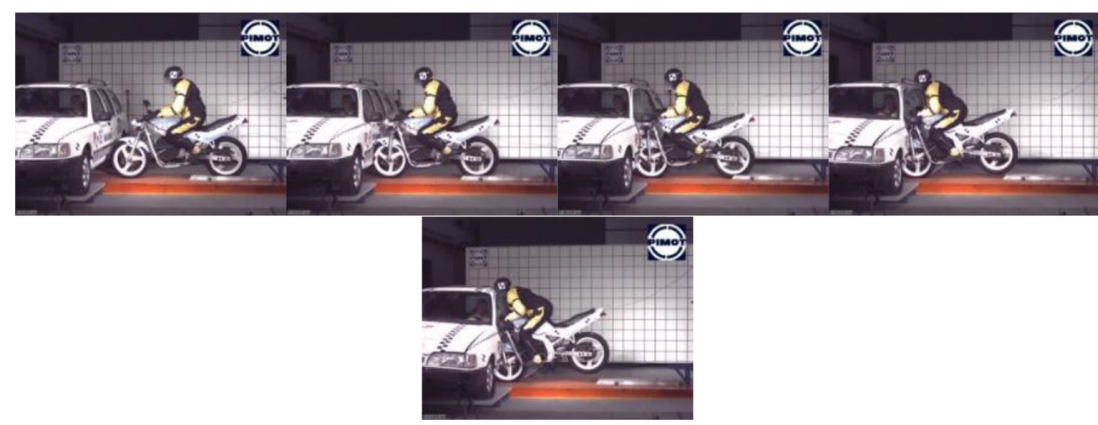

Figure 1: The position of the motorcyclist in the initial phase of striking in the side of the car (from left picture: $\mathrm{t}=0 \mathrm{~s} ; 0.02 \mathrm{~s} ; 0.04 \mathrm{~s} ; 0.06 ; 0.074 \mathrm{~s}$ ). 
the global coordination system (OX and $\mathrm{OZ}$ axes on the Fig. 2) i.e. $\mathrm{a}_{\mathrm{GX}}$ and $\mathrm{a}_{\mathrm{GZ}}$ (for the head) and $\mathrm{a}_{\mathrm{TX}}$ and $\mathrm{a}_{\mathrm{TZ}}$ (for the torso) accordingly.

Components $\mathrm{a}_{\mathrm{GX}}, \mathrm{a}_{\mathrm{GZ}}, \mathrm{a}_{\mathrm{TX}}$ and $\mathrm{a}_{\mathrm{TZ}}$ in the global coordinate system were calculated taking into account the predetermined variables $\beta\left(t_{n}\right)$ and $\varphi_{1}\left(t_{n}\right)$ in discrete moments of the time $t_{n}$ (determined during the frame-by-frame analysis of the video). The angle of rotation of the head and the inclination of the motorcyclist's torso together with the acceleration sensors located there were determined thus. Due to the fact that acceleration sensors were located near to the mass centre of the head and torso, the following relationships were used:

$$
\begin{aligned}
& a_{G X}\left(t_{n}\right)=a_{G x}\left(t_{n}\right) \cos \left[\beta\left(t_{n}\right)\right]+a_{G z}\left(t_{n}\right) \sin \left[\beta\left(t_{n}\right)\right] \\
& a_{G Z}\left(t_{n}\right)=-a_{G x}\left(t_{n}\right) \sin \left[\beta\left(t_{n}\right)\right]+a_{G z}\left(t_{n}\right) \cos \left[\beta\left(t_{n}\right)\right] \\
& a_{T X}\left(t_{n}\right)=a_{T x}\left(t_{n}\right) \cos \left[\varphi_{1}\left(t_{n}\right)\right]+a_{T z}\left(t_{n}\right) \sin \left[\varphi_{1}\left(t_{n}\right)\right] \\
& a_{T Z}\left(t_{n}\right)=-a_{T x}\left(t_{n}\right) \sin \left[\varphi_{1}\left(t_{n}\right)\right]+a_{T Z}\left(t_{n}\right) \cos \left[\varphi_{1}\left(t_{n}\right)\right]
\end{aligned}
$$

where:

$a_{G X}$ and $a_{G Z}$-components of the acceleration vector of the motorcyclist's head in directions: longitudinal $\mathrm{OX}$ and vertical $\mathrm{OZ}$;

$\beta$ - the rotation angle of the motorcyclist's head, $\beta\left(t_{n}=0\right)=\beta_{0}$;

$a_{T X}$ and $a_{T Z}$-components of the acceleration vector of the motorcyclist's torso, as above; $\varphi_{1}-$ the inclination angle of the motorcyclist's torso, $\varphi_{1}\left(t_{n}=0\right)=\varphi_{P}$.

By using the approximation process, time functions have been created from discrete acceleration values $\mathrm{a}_{\mathrm{GX}}\left(\mathrm{t}_{\mathrm{n}}\right)$ and $\mathrm{a}_{\mathrm{GZ}}\left(\mathrm{t}_{\mathrm{n}}\right)$ as well as $\mathrm{a}_{\mathrm{TX}}\left(\mathrm{t}_{\mathrm{n}}\right)$ and $\mathrm{a}_{\mathrm{TZ}}\left(\mathrm{t}_{\mathrm{n}}\right)$. Results of calculations of these time functions $\mathrm{a}_{\mathrm{GX}}(\mathrm{t}), \mathrm{a}_{\mathrm{GZ}}(\mathrm{t}), \mathrm{a}_{\mathrm{TX}}(\mathrm{t}), \mathrm{a}_{\mathrm{TZ}}(\mathrm{t})$ are shown in Figs. $3 \mathrm{a}$ and $3 \mathrm{~b}$, respectively, together with results of measured components of the acceleration vector of the head and torso.

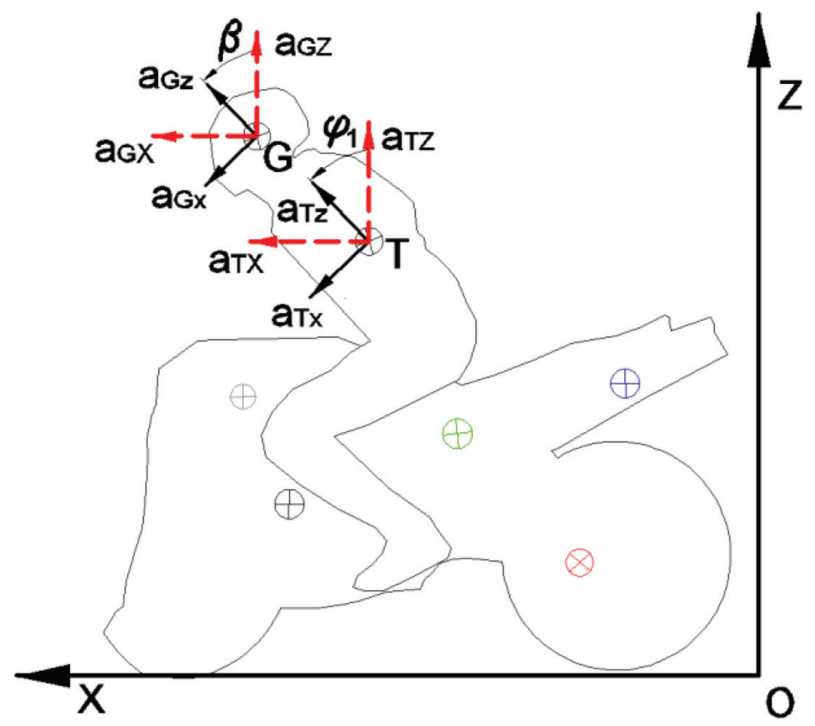

Figure 2: Directions of measured and calculated components of the acceleration vectors of the head $\mathrm{a}_{\mathrm{Gx}}, \mathrm{a}_{\mathrm{Gz}}$ and $\mathrm{a}_{\mathrm{GX}}, \mathrm{a}_{\mathrm{GZ}}$ as well as the torso $\mathrm{a}_{\mathrm{TX}}, \mathrm{a}_{\mathrm{TZ}}$ and $\mathrm{a}_{\mathrm{TX}}, \mathrm{a}_{\mathrm{TZ}}$. 


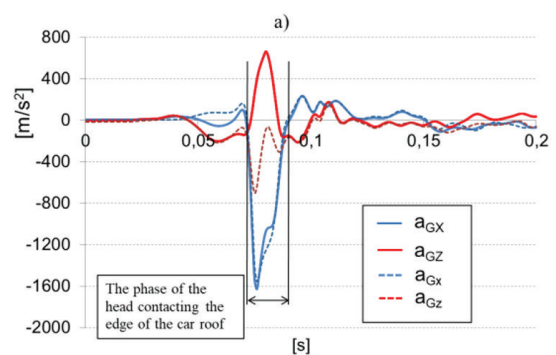

[s]

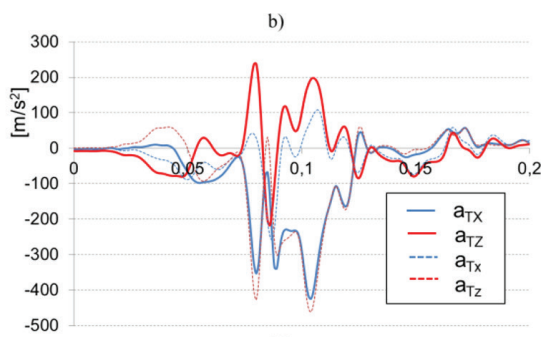

[s]

Figure 3: Measurement results $\mathrm{a}_{\mathrm{Gx}}(\mathrm{t})$ and $\mathrm{a}_{\mathrm{Gz}}(\mathrm{t})$ as well as $\mathrm{a}_{\mathrm{Tx}}(\mathrm{t})$ and $\mathrm{a}_{\mathrm{Tz}}(\mathrm{t})$ (dashed lines) and calculations $\mathrm{a}_{\mathrm{GX}}(\mathrm{t})$ and $\mathrm{a}_{\mathrm{GZ}}(\mathrm{t})$ as well as $\mathrm{a}_{\mathrm{TX}}(\mathrm{t})$ and $\mathrm{a}_{\mathrm{TZ}}(\mathrm{t})$ (continuous lines) of components of the acceleration of the head (a) and torso (b).

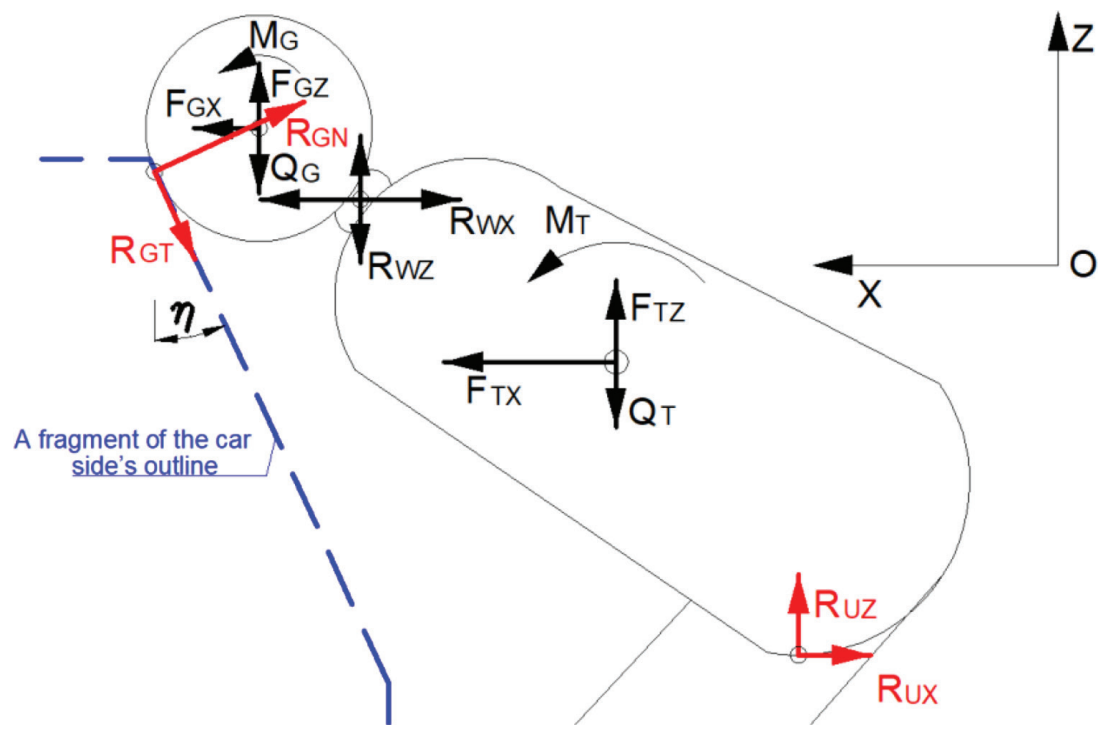

Figure 4: The considered distribution of forces acting on the motorcyclist at the moment of impact $\left(\mathrm{F}_{\mathrm{TX}}, \mathrm{F}_{\mathrm{TZ}}\right.$ - components of the torque force of the torso, $\mathrm{R}_{\mathrm{WX}}, \mathrm{R}_{\mathrm{WZ}}-$ components of the force of the neck node, $\mathrm{F}_{\mathrm{GX}}, \mathrm{F}_{\mathrm{GZ}}$ - components of the inertia force of the head, $\mathrm{R}_{\mathrm{UX}}, \mathrm{R}_{\mathrm{UZ}}$ - the normal and tangential reaction from the motorcycle to the motorcyclist, $\mathrm{R}_{\mathrm{GN}}, \mathrm{R}_{\mathrm{GT}}$ - the normal and tangential component of the reaction from the car to the motorcyclist).

Determined behaviour of acceleration functions of the head $\left(\mathrm{a}_{\mathrm{GX}}, \mathrm{a}_{\mathrm{GZ}}\right)$ and torso $\left(\mathrm{a}_{\mathrm{TX}}, \mathrm{a}_{\mathrm{TZ}}\right)$ is used in calculations of the force (reaction) of the motorcyclist hitting the edge of the roof. Figure 4 shows the distribution of forces that was used in the analysis of the motorcyclist's head impacting the roof edge, i.e. describing the dynamic interaction for $t>0.074 \mathrm{~s}$. From the moment $\mathrm{t}=0.074 \mathrm{~s}$, the normal reaction $\mathrm{R}_{\mathrm{UZ}}$ from the motorcycle [6] to the motorcyclist causes the motorcyclist to rise, resulting in his head hitting the car.

Based on the Fig. 4, the following equations of the balance for forces acting on the head and torso were considered: 


$$
\begin{gathered}
-R_{G N} \cos (\eta)-R_{G T} \sin (\eta)+R_{W X}+F_{G X} \\
R_{G N} \sin (\eta)-R_{G T} \cos (\eta)+R_{W Z}+F_{G Z}-Q_{G} \\
-R_{W X}+F_{T X}-R_{U X}=0 \\
-R_{W Z}+F_{T Z}+R_{U Z}-Q_{T}=0
\end{gathered}
$$

where:

$R_{G T}=\mu_{G} R_{G N} ; R_{U X}=\mu_{T} R_{U Z} ; F_{G X}=-m_{G} a_{G X} ; Q_{G}=m_{G} g ;$

$F_{G Z}=-m_{G} a_{G Z} ; F_{T X}=-m_{T} a_{T X} ; F_{T Z}=-m_{T} a_{T Z} ; Q_{T}=m_{T} g$;

the solution of equations is as follows:

$$
\begin{gathered}
R_{G N}=\frac{-m_{G} a_{G X}-m_{T} a_{T X}+\mu_{A}\left(-m_{G} a_{G Z}-m_{G} g-m_{T} a_{T Z}-m_{T} g\right)}{\cos (\eta)-\mu_{A}\left[\sin (\eta)-\mu_{G} \cos (\eta)\right]+\mu_{G} \sin (\eta)} \\
R_{U Z}=m_{G} g+m_{T} a_{T Z}+m_{G} a_{G Z}+m_{G} g+\left(\mu_{G}-1\right) R_{G N} \cos (\eta)
\end{gathered}
$$

where:

$\mathrm{m}_{\mathrm{G}}$ - the mass of the head and helmet of the motorcyclist;

$\mathrm{m}_{\mathrm{T}}$ - the mass of the torso, legs and hands of the motorcyclist;

$\mathrm{g}$ - the earth acceleration;

$\mu_{\mathrm{G}}$ - the coefficient of the friction of the motorcyclist's wear (the helmet) on the car;

$\mu_{\mathrm{G}}$ - the coefficient of the friction of the motorcyclist's wear (the hip) on the fuel tank;

$\eta$ - the angle of inclination of the car roof edge at the point of contact with the helmet to the vertical.

Values of coefficients $\mu_{\mathrm{G}}$ and $\mu_{\mathrm{A}}$ were determined by measuring the force needed to move hips and the head in the wear (helmet) along the surface being examined. The angle $\eta$ was determined by measuring the inclination of the side of the car and it was assumed that the angle is constant in the phase of contact of the head with the side of the car.

Results of calculations $\mathrm{R}_{\mathrm{GN}}(\mathrm{t})$ and $\mathrm{R}_{\mathrm{UZ}}(\mathrm{t})$ are shown in the Fig. 5.

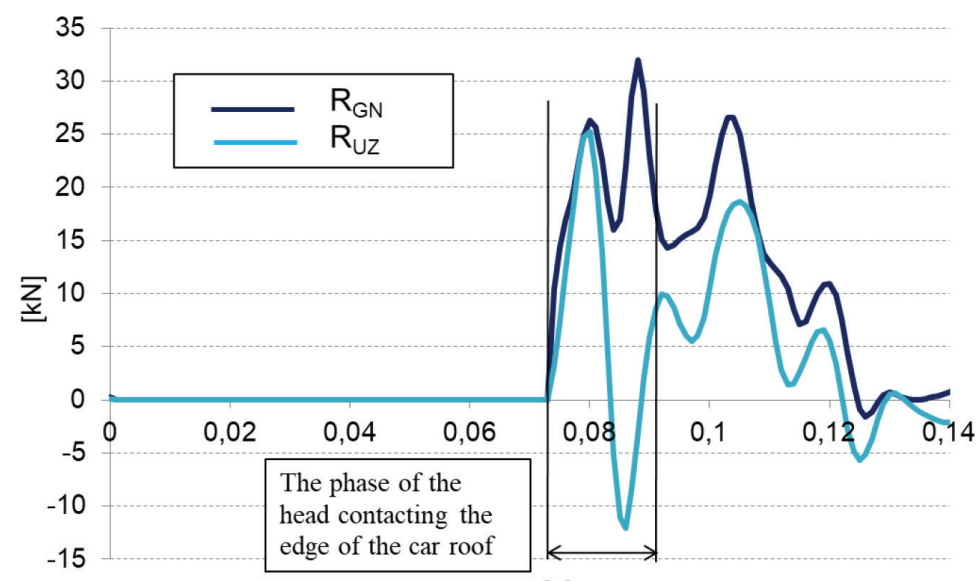

[s]

Figure 5: Results of calculations $\mathrm{R}_{\mathrm{GN}}(\mathrm{t})$ and $\mathrm{R}_{\mathrm{UZ}}(\mathrm{t})$. 
During the phase of the contact of the head with the roof edge ( $t=0.074-0.09 \mathrm{~s})$ the force value of the impact was calculated from the relationship:

$$
R_{G}=\sqrt{R_{G N}^{2}+R_{G T}^{2}}
$$

The maximum value of the hit force of the head in the edge of the roof was $\mathrm{R}_{\mathrm{GMAX}}=36 \mathrm{kN}$.

The course of the deformation of the bodywork of the car - $f_{G}$, i.e. also the dissipation energy of the hit of the motorcyclist as the result of the impact of the head is difficult to estimate. It is related to the course of the force $\mathrm{R}_{\mathrm{GN}}$, which caused the deformation of the roof of the car. In calculations of the work done by deformation force for the roof edge, it was assumed that the maximum deformation depth $\left(\mathrm{f}_{\mathrm{GMAX}}\right)$ occurred when the reaction $\mathrm{R}_{\mathrm{GN}}$ reached the maximum, hence the maximum value of the work done by deformation force of the car body was calculated from the equation:

$$
W D 1_{M A X}=R_{\text {GNMAX }} f_{\text {GMAX }}
$$

The maximum depth of the deformation was determined by measuring the depth of deformation of the car at the place of the impact of the motorcyclist's head. Results of the calculation of the normal hit force, i.e. $\mathrm{R}_{\mathrm{GN}}$, and the course of the work done by force deforming the car body (WD1) are shown in the Fig. 6.

\section{EXPERIMENTAL RESEARCH OF THE HELMET}

A research was conducted to determine the helmet deformation characteristics that would allow to estimate the work done by force deforming the helmet. This characteristic was determined at the test stand (Fig. 7a), in which the head model in the helmet was placed on a pendulum arm. The model hit the anvil with the energy of $60 \mathrm{~J}$. Characteristics of the helmet deformation established on the basis of the experiment, are shown in the Fig. $7 \mathrm{~b}$.

Forces at the point of the head impacting the edge of the roof caused the deformation of the helmet, but the outer shell was not damaged. This allowed to conduct the experiment which

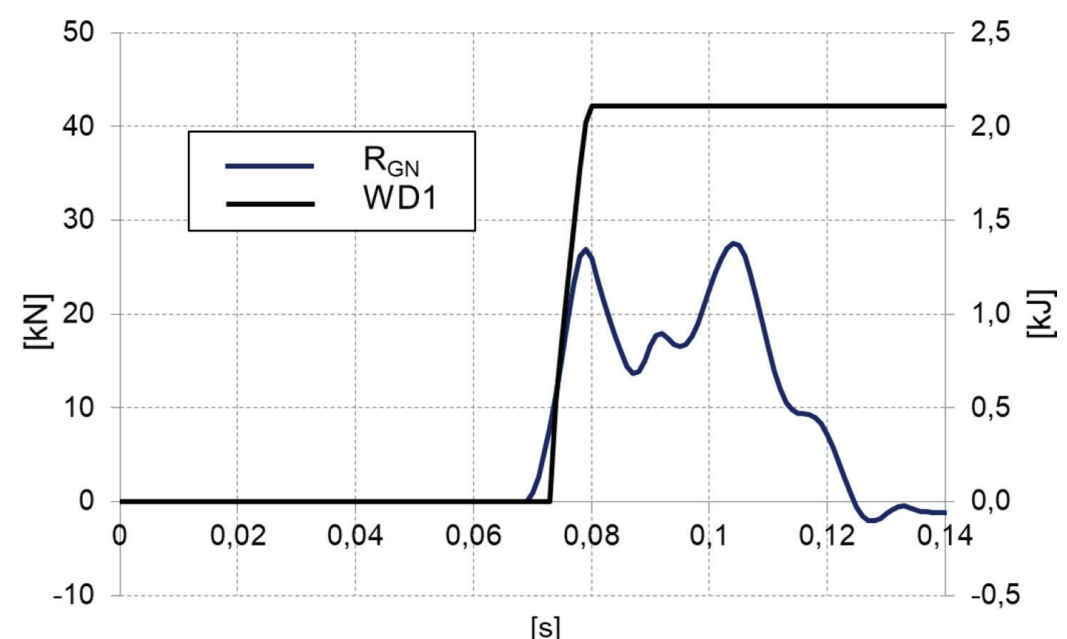

[s]

Figure 6: Results of calculations of the work done by deformation force for the car bodywork as the result of the motorcyclist's interaction - WD1 and $\mathrm{R}_{\mathrm{GN}}$. 
a)

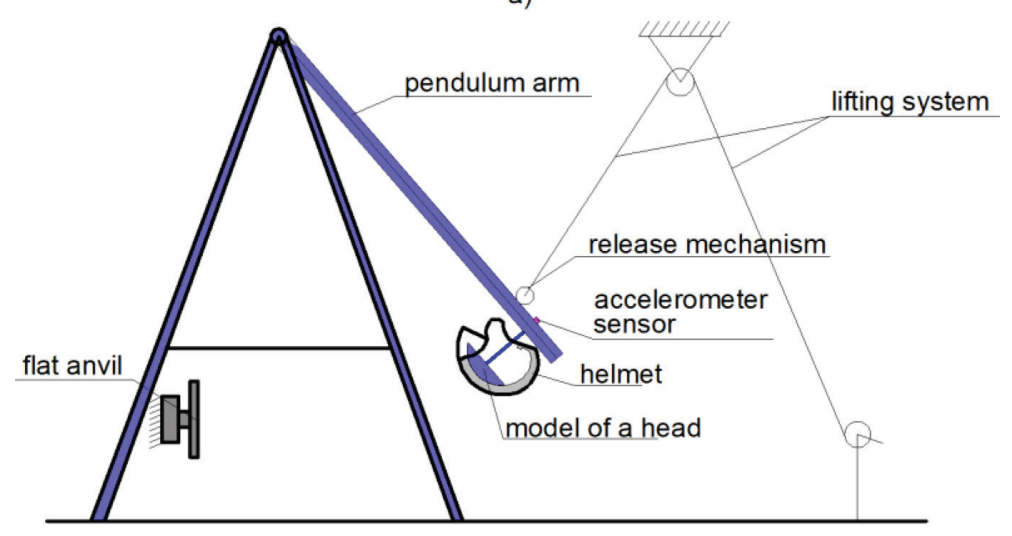

b)

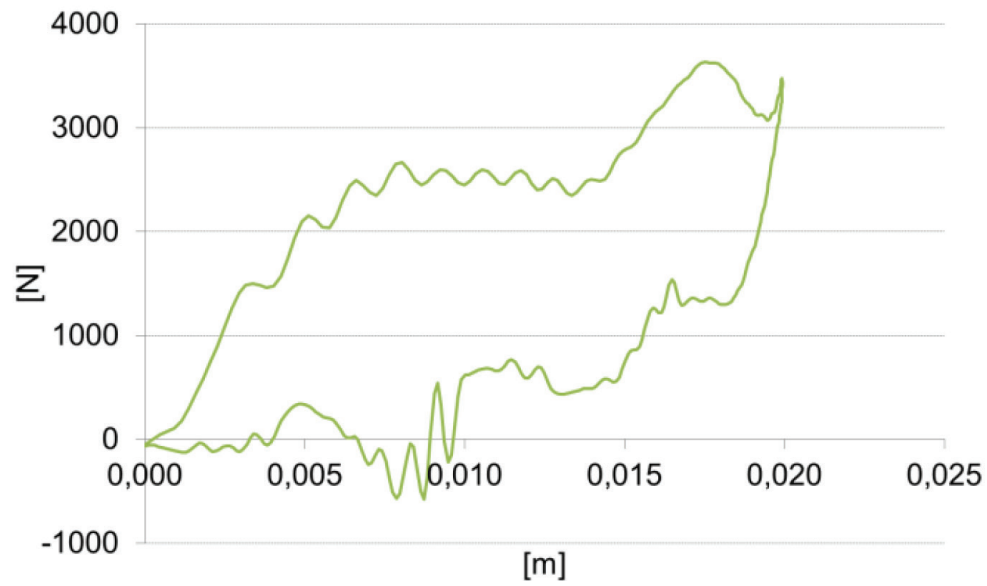

Figure 7: The stand for determining characteristics of the helmet deformation (a); the characteristic of the helmet deformation based on measurement results (b).

showed that at the hit force of only $3.6 \mathrm{kN}$ the depth of the helmet deformation was $\mathrm{d}_{\mathrm{K}}=0.02 \mathrm{~m}$. Thus, during the hitting the head, the force acting on the helmet has depleted the deformation potential of the energy-absorbing lining and the inner layer [5]. Then the impact force affects directly the motorcyclist's head. Based on this, the maximum value of the helmet deformation was assumed to be equal to $\mathrm{d}_{\mathrm{K}}=0.02 \mathrm{~m}$, and the permissible local head deformation equal to $\mathrm{d}_{\mathrm{G}}=0.01 \mathrm{~m}$ was added to it (based on [10]), thus making the $\mathrm{d}_{\mathrm{KMAX}}=30$ $\mathrm{mm}$. Taking the above into account, the maximum work done by deformation force of the helmet was calculated from the equation:

$$
W K 1_{M A X}=R_{G N M A X} d_{K M A X}
$$

The result of the calculating the work done by force deforming the motorcyclist's helmet (WK1 and $\mathrm{R}_{\mathrm{GN}}$ ) is shown in the Fig. 7. 


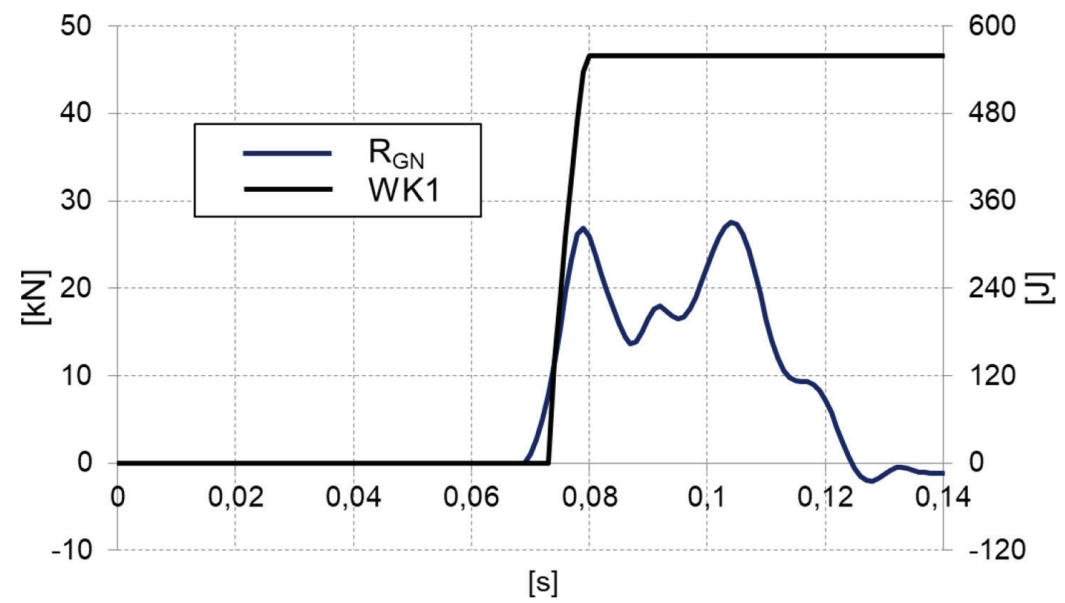

Figure 8: The work done by force deforming the motorcyclist's helmet - WK1 and $\mathrm{R}_{\mathrm{GN}}$.

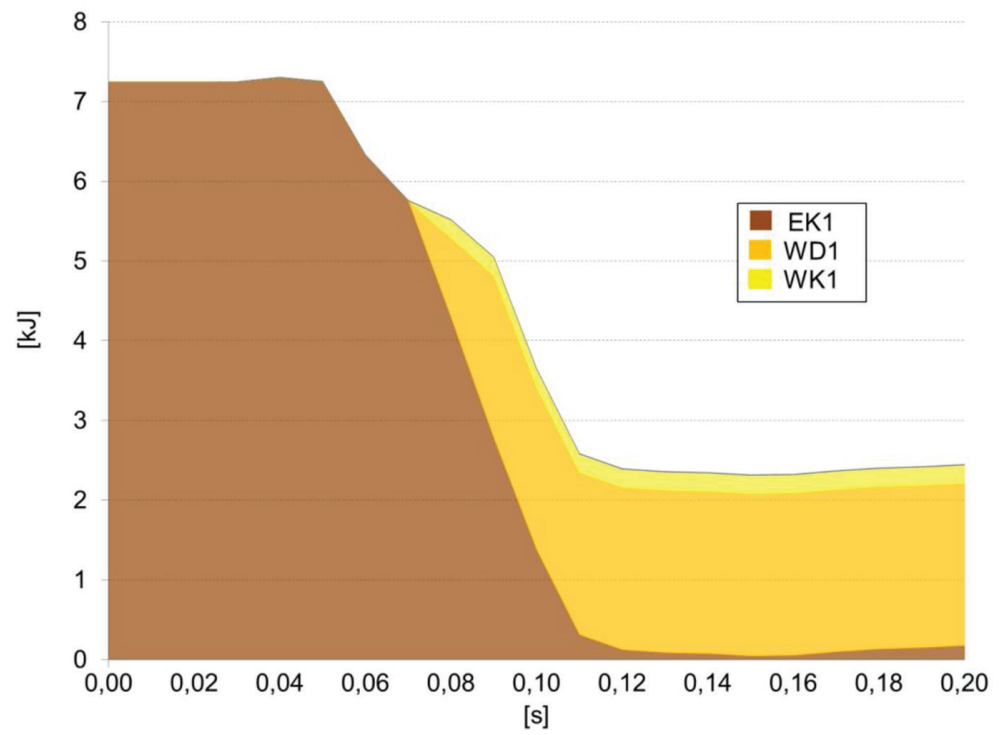

Figure 9: Results of calculations of the kinetic energy of the motorcyclist (EK1) and work done by force deforming the car WD1 and the helmet WK1.

Results of calculations are listed in the Fig. 9:

- the kinetic energy of the motorcyclist before the collision (EK1);

- the work done by force deforming the side of the car due to the impact of the motorcyclist's head (WD1);

- the work done by force deforming the helmet due to the impact of the car (WK1).

From these calculations, the head hitting the side of the car leads to the energy dissipation of $\mathrm{WD} 1+\mathrm{WK} 1=2.3 \mathrm{~kJ}$, which represents $32 \%$ of the kinetic energy of the motorcyclist. 


\section{EXPERIMENTAL RESEARCH OF MATERIALS ABSORBING THE IMPACT ENERGY}

The general protective function of the motorcyclist's helmet is met by a protective layer: the inner layer, the energy-absorbing lining and the outer shell. A test stand was built where the model of head was attached to a pendulum arm (Fig. 10). Research concerned the evaluation of dynamic properties of materials and consisted of hitting head on a fragment of an energy-absorbing material attached to the anvil. 10 different materials [5] were selected, including the material (EPS 60) previously used in the helmet used during the crash experiment. An impact with the energy of $60 \mathrm{~J}$ was considered. The value of the impact energy was chosen taking into account the fact that according to [11], the skull fracture can occur when the head hit a rigid obstacle with the energy of 22-24 J, and with the energy of 14-68 J according to [12].

At this stage of the analysis of dynamic loads, the extreme acceleration values of the head and the force and energy of the indentation of the material samples into the inside of the helmet while hitting the head model were considered. Performed measurements allowed to determine the force and work characteristics in the function of the deformation as shown in the Fig. 11 as well as in the Table 1. From the whole set of studied materials, the attention was focused on those selected for the Table 1. Table 1 summarizes the maximum values of the resultant acceleration of the head $\mathrm{a}_{\mathrm{W}}$ and the force and work values of the deformation of the material.

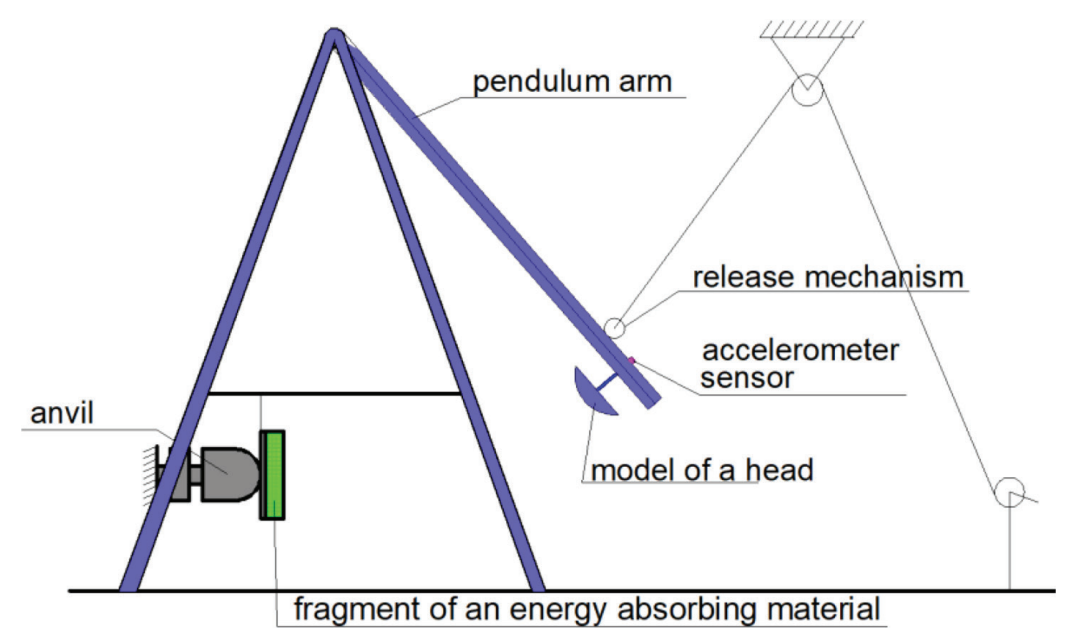

Figure 10: The scheme of the test stand for research energy absorbing material.
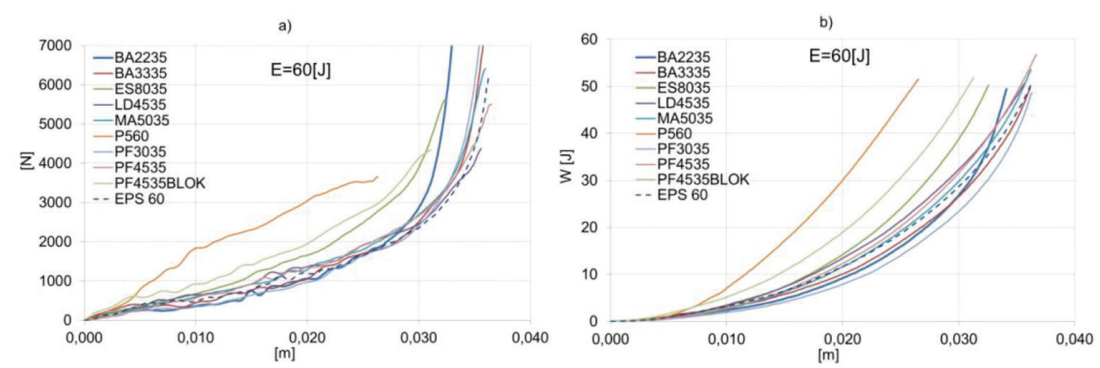

Figure 11: The force and work in the function of the samples deformation [5]. 
Table 1: Maximum values of dynamic loads on the head, and forces and the dissipated energy at the deformation of $25 \mathrm{~mm}$.

\begin{tabular}{lllll}
\hline Energy-absorbing material & Material density $\left[\mathrm{kg} / \mathrm{m}^{3}\right]$ & aw $\left[\mathrm{m} / \mathrm{s}^{2}\right]$ & $\mathrm{W}[\mathrm{J}]$ & Force $[\mathrm{N}]$ \\
\hline LD4535 & 45 & 245 & 20.7 & 1632 \\
PF4535BLOK & 45 & 265 & 29.5 & 2650 \\
EPS60 & 60 & 255 & 18.4 & 1871 \\
\hline
\end{tabular}

The comparison of properties of considered energy-absorbing helmets linings indicates that despite the slight differences in the course of energy dissipation, the use of LD4535 material instead of the EPS60 material may lead to the reduction of the maximum head load by approximately $4 \%$. This does not provide for considerable possibility of minimizing dynamic loads and injuries. However, when approaching the boundary of biomechanical resistance of the head for the impact, these few percent may enable the motorcyclist to survive the road accident.

\section{RECAPITULATION AND CONCLUSIONS}

Experimental research was conducted, which included:

- the front-side collision test of a motorcyclist with a car;

- the determination of the helmet deformation characteristics;

- the identification of dynamic properties of energy-absorbing materials for the inner lining of motorcycle helmets.

Results of measurements performed during experiments were used for:

- calculating the force of the motorcyclist's head hitting the side of the car bodywork;

- determining the energy balance components related to the vehicle deformation as a result of the motorcyclist's interaction and the helmet deformation;

- comparing properties of energy-absorbing linings of considered helmets.

During the analysed traffic accident, the motorcyclist's head hit the side of the car with the force which maximum value was $\mathrm{R}_{\mathrm{GMAX}}=36 \mathrm{kN}$. This force caused the deformation of the side of the car and the helmet. Already the force of $3.6 \mathrm{kN}$ can deplete the potential for deformation of the energy-absorbing material of the helmet, and as a result, the further increase in the strike force directly affects the motorcyclist's head.

Results of the analysis process for the deformation of the body of the car and the helmet were the basis for calculating the energy dissipation of the motorcyclist's head. The energy dissipated as the result of the head hitting the side of the car represented $32 \%$ of the kinetic energy of the motorcyclist before the collision. In turn, the analysis of dynamic properties of energy-absorbing materials indicated that despite the slight differences in the course of the energy dissipation, the use of LD4535 material instead of the EPS60 material may lead to the reduction of the maximum head strain by approximately $4 \%$. 


\section{REFERENCES}

[1] Adamson, K., Alexander, P., Robinson, E.L., Johnson, G.M., Burkhead, C.I., Mcmanus, J., Anderson, G.C., Aronberg, R., Kinney, J.R. \& Sallmann, D.W., Seventeen MotorCycle Crash Tests into Vehicles and a Barrier, SAE Technical Paper, 2002.

[2] Chawla, A., Mukherjee, S., Mohan, D., Bose, D., Rwawat, P., Sakurai, M. \& Nakatani, T., FE Simulations of motorcycle - car frontal crashes, validation and observations. The 18th ESV Conference Proceedings, Nagoya, 2003.

[3] Unarski, J., Uderzenie motocykla w bok samochodu będącego w ruchu (The motorcycle impact on the side of a moving car). Wydawnictwo Instytutu Ekspertyz Sądowych. Paragraf na drodze, nr 2, 2009.

[4] Pinnoji, K.P., Haider, Z. \& Mahajan, P., Design of motorcycle helmets: computational fluid and impact analysis. International Journal of Crashworthiness, 13(3), pp. 265-278, 2008. https://doi.org/10.1080/13588260801933626

[5] Pusty, T. \& Prochowski, L., Analiza wyników badań materiałów energochłonnych do wypetnienia hetmu motocyklowego, XXXII Seminarium Kół Naukowych Wydziału Mechanicznego, Wojskowa Akademia Techniczna, Warszawa, 2013.

[6] Prochowski, L., Pusty, T. \& Zielonka, K., Major components of the energy balance in the process of a motorcycle impact against a motor car side, 25th Annual Congress of the EVU 2016.

[7] Prochowski, L. \& Pusty, T., Bilans energii procesu uderzenia motocykla w bok samochodu (Balance of energy in the process of a motorcycle impact against a motorcar side). X International Science-Technical Conference Automotive Safety 2016. Problemy bezpieczeństwa w pojazdach samochodowych. Wydawnictwo Politechniki Świętokrzyskiej, Kielce 2016.

[8] Burg, H. \& Moser, A., Handbuch Verkehrsunfallrekonstruktion Unfallaufnahme, Fahrdynamik, Simulation, 2 Auflage, Springer, Wiesbaden, 2009.

[9] Priester, J., Weyde, M. \& Kasanicky, G., Motorrad-Kollisions-versuche mit Geschwindigkeiten 78-122 km/h, Verkehrsunfall und Fahrzeugtechnik, Heft 9, 2002.

[10] Tejszerska, D., Świtoński, E. \& Gzik, M., Biomechanika narzqdu ruchu człowieka, Wydawnictwo Naukowe Instytutu Technologii Eksploatacji - PIB, Radom, Gliwice, 2011.

[11] Delye, H., Verschueren, P., Depreitere, B., Verpoest, I., Berckmans, D., Sloten, J.V., Perre, G.V.R. \& Goffin, J., Biomechanics of frontal skull fracture. Journal of Neurotrauma, 24, pp. 1576-1586, 2007. https://doi.org/10.1089/neu.2007.0283

[12] Yoganandan, N., Pintar, F.A., Sances, A., Walsh, P.R., Ewing, C.L., Thomas, D.J. \& Snyder, R.G., Biomechanics of skull fracture. Journal of Neurotrauma, 12, pp. 659-668, 1995.

https://doi.org/10.1089/neu.1995.12.659 